\title{
Effect of Neonatal Infraorbital Nerve Transection on Substance P. and Leucine Enkephalin-like Immunoreactivities in Trigeminal Subnucleus Caudalis of the Rat
}

\author{
Robert W. Rhoades, Nicolas L. Chiaia, Paul R. Hess, and Michael W. Miller \\ Department of Anatomy, University of Medicine and Dentistry of New Jersey, School of Osteopathic Medicine and \\ Robert Wood Johnson Medical School, Piscataway, New Jersey 08854
}

\begin{abstract}
The distributions of substance P-like immunoreactivity (SPLI) and leucine-enkephalin-like immunoreactivity (LENKLI) in subnucleus caudalis of normal adult rats were compared with those observed in the adult rats that sustained transection of the infraorbital (IO) nerve either on the day of birth or in adulthood. All immunocytochemical experiments in the neonatally nerve damaged rats were carried out at least 60 $d$ after the nerve transection. In the animals that sustained nerve transections as adults, brains were processed for immunohistochemistry between 7 and $60 \mathrm{~d}$ after the lesions. In the rats that sustained 10 nerve transections as adults, there was a transient reduction in the density of the SPLI in layers I and II of ipsilateral subnucleus caudalis. It was most apparent about 2 weeks after the nerve transection and returned to near normal values by $60 \mathrm{~d}$ after the lesion. In the rats that sustained 10 nerve transections on the day of birth, there was no reduction in the density of SPLI in caudalis, and the band of staining on the deafferented side of the brain stem was actually $\mathbf{4 0} \%$ wider than that on the intact side. Neither neonatal nor adult 10 nerve transection had appreciable effects upon the distribution of LENKLI in the rat's trigeminal brain-stem complex.

In another series of experiments, rats that sustained neonatal transection of the 10 nerve had this same nerve recut in adulthood. Twelve days after the second lesion, the brains of these animals were processed for SPLI. There was a marked reduction in the density of the staining for this peptide on the deafferented side. This last result is consistent with the interpretation that the increased distribution of SPLI in the neonatally nerve damaged rats is due, at least partially, to reorganization of primary afferents.
\end{abstract}

There is a substantial literature, recently reviewed by Aldskogius et al. (1985), concerned with the effects of peripheral nerve damage upon the primary afferent innervation of the spinal cord and brain stem. Most studies that have addressed this issue can be grouped into one of two types: those that have examined

\footnotetext{
Received Apr. 13, 1987; revised Nov. 11, 1987; accepted Nov. 11, 1987.

This work was supported in part by DE 07734 and a grant from the UMDN.I Foundation (R.W.R. and M.W.M.), BNS 85-17537 (R.W.R.), and AA 06916 (M.W.M.). N.L.C. was supported by grant NRSA NS 07774. Thanks to Zebetta Allen, Anne C. Lewin, and Lisa Modarressi for excellent technical assistance and to Patti Vendula for typing the manuscript. Thanks also to Dr. Gordon MacDonald for supplying the animals used in this project.

Correspondence should be addressed to Dr. Robert W. Rhoades, Department of Anatomy, UMDNJ-SOM, 675 Hoes Lane, Piscataway, NJ 08854.

Copyright (C) 1988 Society for Neuroscience $0270-6474 / 88 / 072234-14 \$ 02.00 / 0$
}

effects of nerve damage upon all primary afferents from a given nerve using anterograde or retrograde tract tracing techniques (e.g., Grant and Arvidsson, 1975; Westrum et al., 1976; Sugimoto and Gobel, 1982; Jacquin and Rhoades, 1983, 1985; Seltzer and Devor, 1984; Arvidsson, 1986) and those that have concentrated upon subsets of afferents that could be demonstrated by either histochemical or immunohistochemical staining (e.g., Rustioni et al., 1971; Knyihar and Csillik, 1976; Jessel et al., 1979; McGregor et al., 1984; Tessler et al., 1985).

In considering the central consequences of peripheral nerve damage, it is important to correlate data for all of the fibers comprising a given regenerate nerve with those that can be obtained by demonstrating neurochemically distinct subsets of these axons immunocytochemically. The utility of such experiments resides in that they may provide information regarding the type(s) of fibers that retain or reestablish their central projections after transection of their peripheral axons (Fitzgerald, 1985; Fitzgerald and Vrbová, 1985).

The infraorbital (IO) nerve and its innervation of the trigeminal (V) brain-stem complex in rodents offers an interesting opportunity to carry out such correlative experiments for several reasons. First, the central distribution of axons from this $\mathrm{V}$ branch in normal adult rats has been defined with anterograde tracing methods (Arvidsson, 1982; Jacquin and Rhoades, 1983). Second, the effects of damage to this nerve have been well defined with these techniques. Transection of the IO nerve in adult rats produces no change in the overall distribution of its central terminals as demonstrated by transganglionic transport of HRP (Renehan et al., 1986). Neonatal transection of the nerve, on the other hand, results in a major reduction in the density of staining in $\mathrm{V}$ nucleus principalis, subnucleus oralis, subnucleus interpolaris, and the magnocellular portion of subnucleus caudalis (Jacquin and Rhoades, 1983, 1985; Chiaia et al., 1987). A dense projection to layers I and II of caudalis is, however, retained. A third reason that the IO nerve and its innervation of the $\mathrm{V}$ brain-stem complex is interesting for examination of subsets of primary afferents after damage is that the distributions of several peptides thought to be contained in primary afferent terminals, and in particular substance $P$, have been well described for this region (e.g., Hökfelt et al., 1975; Ljungdahl et al., 1978; Cuello et al., 1978; Cuello and Kanazawa, 1978; Del Fiacco and Cuello, 1980; Sakanaka et al., 1982; Cuello et al., 1985).

For these reasons, we decided to evaluate the effects of neonatal and adult IO nerve transection upon the distribution and density of substance P-like immunoreactivity (SPLI) in the rat's $V$ brain-stem complex. In these same animals, we also assessed 
the distribution of leucine-enkephalin-like immunoreactivity (LENKLI). This peptide has a distribution in caudalis that matches, fairly closely, that of substance P (Simantov et al., 1977), and it is thought to arise from brain-stem neurons rather than primary afferents (Hökfelt et al., 1977).

\section{Materials and Methods}

Experimental animals. In all, 34 Sprague-Dawley rats were employed in this study; 5 were normal adults, 18 were adults $(60-75 \mathrm{~d}$ of age) that had sustained transection of the IO nerve within $12 \mathrm{hr}$ of birth, and 11 were adults (120-180 d of age) that received transections of the IO nerve between 7 and $60 \mathrm{~d}$ prior to sacrifice.

Nerve transections. All neonatal nerve transections were carried out after animals were anesthetized by placement on a bed of crushed ice. The IO nerve was exposed just behind the vibrissal pad and transected according to the methods that have been described by Jacquin and Rhoades $(1983,1985)$. No attempt was made to reapproximate the cut ends of the nerve, and the facial wound was closed with cyanoacrylate. After surgery, pups were rewarmed and returned to their mothers.

Adult nerve transections were accomplished under sodium pentobarbital anesthesia. These animals were placed in a headholder, and the IO nerve was exposed caudal to the vibrissal pad. It was then transected, and the wound was closed. As in the neonates, no attempt was made to bring the proximal and distal stumps of the nerve into apposition.

In 3 animals that sustained neonatal transection of the IO nerve, this $\mathrm{V}$ branch was recut $12 \mathrm{~d}$ prior to sacrifice. In these rats, the nerve was transected in the orbit according to methods that have been detailed by Jacquin et al. (1984).

Perfusion and tissue processing. Rats were deeply anesthetized with ether and killed by transcardial perfusion. After a saline wash, 250-300 $\mathrm{ml}$ of $4.0 \%$ paraformaldehyde in $0.10 \mathrm{M}$ sodium phosphate buffer $(\mathrm{pH}$ 7.4) was slowly perfused over $30 \mathrm{~min}$. The fixative was washed out with $100-150 \mathrm{ml} 10 \%$ sucrose buffer, which also served as a cryoprotectant. Immediately after the perfusion was complete, the brain was removed and stored overnight in $30 \%$ sucrose buffer at $4^{\circ} \mathrm{C}$. The next day, a complete series of $40-\mu \mathrm{m}$-thick coronal or horizontal sections was cut with a freezing microtome. Three series composed of every third section were made; one was processed for SPLI, one for LENKLI, and the third was stained with cresyl violet.

The distributions of SPLI and LENKLI were determined using the immunoperoxidase procedure of Hsu et al. (1981). Accordingly, freefloating sections were washed in $3.0 \%$ goat serum in $0.10 \mathrm{~m}$ sodium phosphate buffer ( $\mathrm{pH} 7.4$ ) incubated with a primary antibody for 16$18 \mathrm{hr}$ at $4^{\circ} \mathrm{C}$. The 2 primary antibodies were polyclonal antibodies directed against rabbit substance $\mathrm{P}$ or leu-enkephalin, conjugated to keyhole limpet hemocyanin and were generated in goats (Immuno Nuclear Corp). The primary antibodies were diluted in a solution of $3.0 \%$ goat antiserum and $0.4 \%$ Triton $X$ in $0.10 \mathrm{M}$ sodium phosphate buffer (pH 7.4). The working dilutions were $1: 3500$ and 1:2000 for the antisubstance $P$ and anti-enkephalin, respectively. Subsequently, the tissue was immersed in a $0.45 \%$ solution of biotinylated goat anti-rabbit antibody for $60-90 \mathrm{~min}$ and then a $1.8 \%$ solution of avidin-bound peroxidase (Vector) for $45 \mathrm{~min}$. Both the secondary antibody and the peroxidase solutions were diluted in $3.0 \%$ goat serum in $0.10 \mathrm{M}$ phosphate buffer. The peroxidase was mixed with $0.017 \%$ hydrogen peroxide in a solution of $1.5 \%$ diaminobenzidine in Tris buffer $(\mathrm{pH} 7.4)$ for $7-10 \mathrm{~min}$ at room temperature. Reacted sections were mounted on chrom-alum subbed slides, dehydrated, cleared, and coverslipped.

A series of 3 controls for the immunocytochemical reaction were performed. In the first 2 controls, the tissue was processed without being incubated with either the primary or the secondary antibody. These controls represent a test of antibody specificity. In the third control, a solution of primary antibody that had been mixed with an excess of antigen ( $10 \mu \mathrm{g} / \mathrm{ml}$; Peninsula Labs) was substituted for the primary antibody. This preabsorption served as a control for antibody specificity, as well as providing background levels. No immunoreactivity was evident in any of these control experiments.

Data analysis. Since both SPLI and LENKLI were confined almost completely to subnucleus caudalis in all 3 groups of animals (see Results), our analyses were restricted to this region. All of the photographs used to illustrate our findings for the different experimental conditions were taken, developed, and printed under identical conditions.

Quantitative estimates regarding the distributions of SPLI and LENK-
LI were obtained from 5 neonatally nerve-damaged rats in the following manner. Every Nissl-stained section through caudalis was traced, and the boundaries between the V spinal tract (TrV), lamina I-II, and lamina III were added to these drawings. The boundaries of the regions in which heavy SPLI and LENKLI were observed were also charted separately. These drawings were then used to compute the average cross-sectional area of layers I and II and the average width of these laminae in the center of the region innervated by IO primary afferents (Jacquin and Rhoades, 1983). Cross-sectional areas, perimeters, and widths of SPLI and LENKLI were obtained in the same manner. All of these measurements were made with the aid of a graphics tablet that was interfaced to an IBM PC. Effects of nerve damage were evaluated by comparing data from the intact and deafferented sides of the brain stem (with paired $t$ tests). Each animal contributed a single data point to each of these analyses.

The relative densities of the SPLI on the partially deafferented and intact sides of the brain stem in the different preparations were estimated in the following manner: $35 \mathrm{~mm}$ Ektachrome slides of 5 sections (spaced at $150 \mu \mathrm{m}$ ) through subnucleus caudalis were taken for each animal. All of these slides were taken and processed at the same time. The maximum optical density of SPLI was determined along each of 4 lines perpendicular to layers I and II. Each of these lines was within the terminal field of the IO nerve. The 4 readings for a given side of each section were averaged, and mean density for each side in each animal was then computed. These means were used to obtain a ratio between the density of the SPLI on the 2 sides of the brain stem for each rat. Data from each group of nerve-damaged animals were then compared with those from normals by means of independent $t$ tests. The validity of this approach was tested in 2 ways. First, ratios were computed for 5 normal rats using the methods described above. In these animals, the expected ratio between the average density of SPLI on the 2 sides of the brain stem is 1.0. The observed average ratio was $0.97(\mathrm{SD}=0.14)$. We also validated this method by comparing, in the manner described above, the density of SPLI on the 2 sides of the fourth cervical segment of the spinal cord of each of the nerve-damaged animals. Here again, the expected ratio was 1.0 , and the observed value was $1.11(\mathrm{SD}=$ 0.12 ).

\section{Results}

With the exception of an occasional labeled fiber, nucleus principalis (Fig. $1 E$ ) and subnucleus oralis (Fig. $1 F$ ) were nearly devoid of SPLI. This was also true for the rostral portion of subnucleus interpolaris. In the caudal part of interpolaris (Figs. $1 G$, arrow; $2 A$ ), however, there was a region dorsal to the nucleus itself that contained a dense meshwork of heavily labeled fibers. This area (Fig. 2C) was composed of relatively dense accumulations of small cell bodies and appeared very different from more lateral and ventral regions of $\operatorname{TrV}$ (Fig. 2B). This region has been referred to as the paratrigeminal nucleus (Paxinos and Watson, 1982). There were also occasional "pockets" of SPLI within the caudal portion of interpolaris itself (Fig. $2 D$, open arrow).

The densest SPLI in the V brain-stem complex was localized in layers I and II of subnucleus caudalis (Figs. $1 H, 3 A$ ). The outermost part of layer I (Fig. $3 A$, arrows) was relatively devoid of SPLI, and heavy immunoreactivity began just ventral to this region. In addition, the heavy SPLI did not extend to the ventral border of lamina II, but occasional stained fibers were visible in the inner portion of this lamina and in layers III-V (Fig. $3 D$ $F$ ).

\section{Normal distribution of LENKLI in the rat's V brain-stem complex}

The distribution of LENKLI was similar to that of SPLI in the $\mathrm{V}$ brain-stem complex (compare Fig. $1 E-H$ with $I-L$ ). This similarity extended to the existence of a dense and previously unreported (for rat, but see Shults et al., 1985, for corresponding data from cat) plexus of immunoreactive fibers in the paratri- 


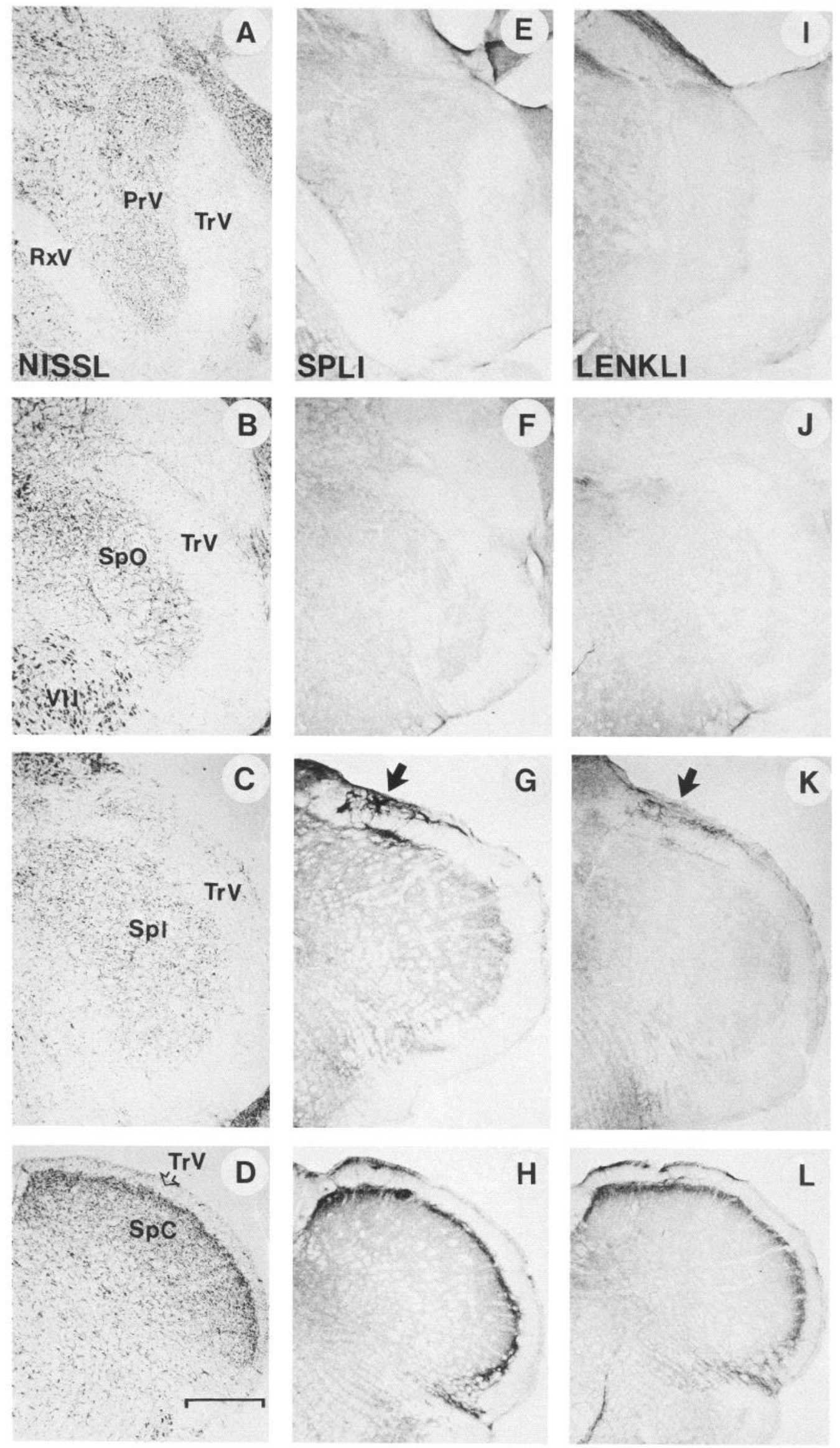



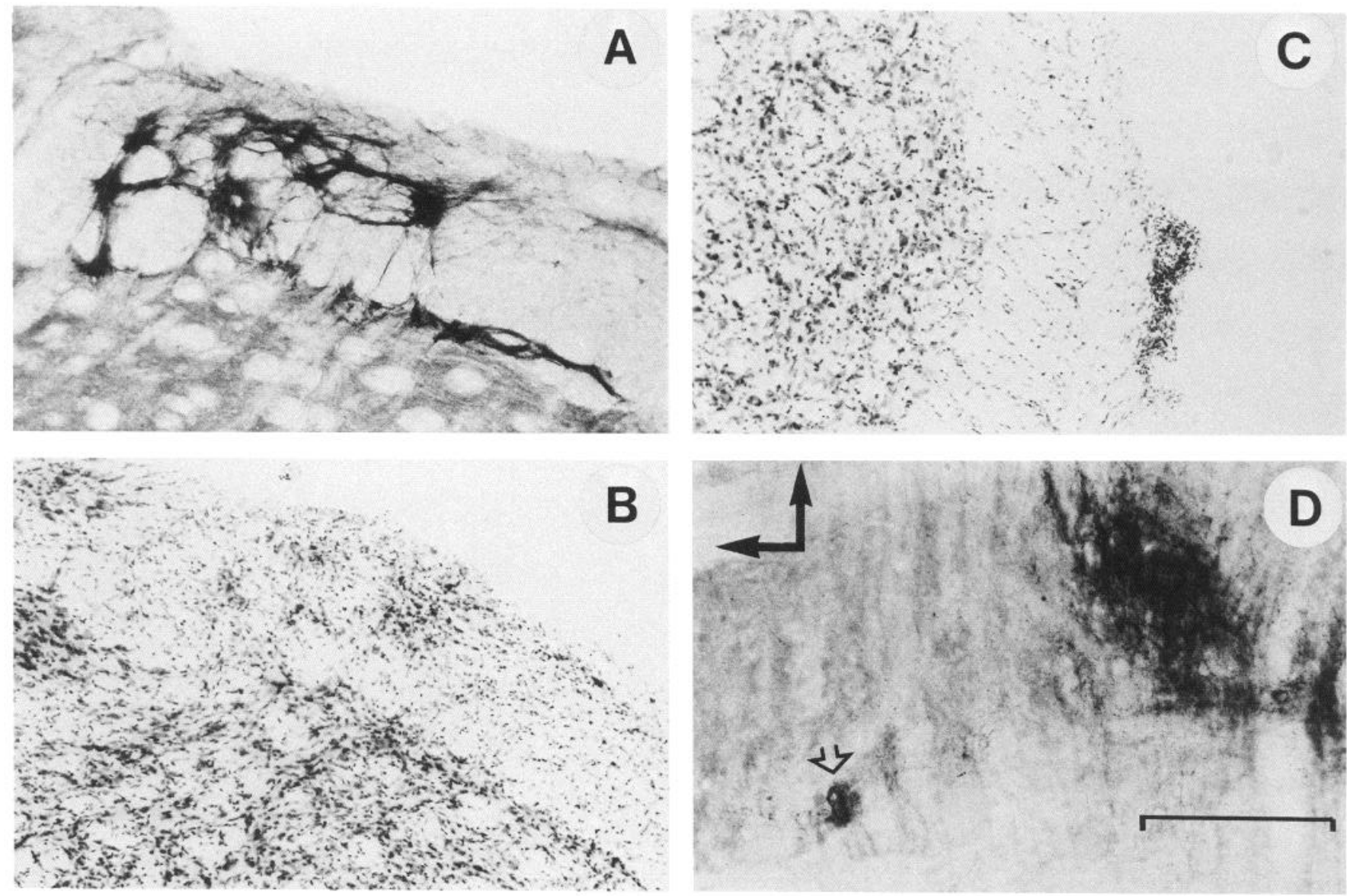

Figure 2. Photomicrographs illustrating SPLI in the caudal portion of subnucleus interpolaris. A, Dense meshwork of SPLI in the paratrigeminal nucleus. $B$, Same region in a section stained for Nissl substance. Note the clusters of small cells. $C$, Another portion of TrV. Note the lack of stained neurons. $D$, Photomicrograph of a horizontal section (solid arrows point toward rostral and lateral) illustrating an interstitial pocket of SPLI (open arrow). Calibration bar, $250 \mu \mathrm{m}(A-D)$.

geminal nucleus (Figs. $1 K$, arrow; $4 A$ ). LENKLI was also visible in the interstitial pockets in the caudal portion of subnucleus interpolaris (Fig. 4B). As was case for SPLI, heavy LENKLI did not extend all the way to the dorsal border of lamina I (Fig. $4 C$ $E$ ). On the other hand, heavy immunoreactivity was visible deeper in layer II than was the case for SPLI (compare Figs. 3 and 4). Immunoreactive fibers, as well as an occasional immunoreactive cell, could also be seen in the magnocellular laminae of caudalis (Fig. 4, $F, G$ ).

\section{Effects of adult transection of the IO nerve upon the distributions of SPLI and LENKLI in the V brain-stem complex}

Transection of the IO nerve in adult rats produced a significant reduction in the density of SPLI in the portion of caudalis normally innervated by the IO nerve (Table 1A). This change was most readily visible 10-14 d after the lesion (compare Fig. 5, $A$ and $B$ ). By $60 \mathrm{~d}$ after the nerve transection (Fig. 5, $D, E$ ), the density of SPLI in caudalis had returned to near normal levels (Table 1B). There was no appreciable change in the laminar distribution of SPLI at any point following the IO nerve lesion. Transection of the IO nerve in adult rats produced no change in the distribution or density of LENKLI in the trigeminal brainstem complex (Fig. 5, F, G). We also observed no qualitative changes in the cytoarchitectonic organization of subnucleus caudalis in the rats that sustained adult transections of the IO nerve.

\section{Effect of neonatal transection of the IO nerve upon SPLI and LENKLI in the V brain-stem complex of the adult rat}

The effects of neonatal IO nerve damage were qualitatively different from those observed after adult damage of this $\mathrm{V}$ branch. Neonatal transection of the IO nerve produced no significant reduction in the density of SPLI on the deafferented side of the brain stem (Table 1C). In fact, the average ratio between the SPLI densities on the partially deafferented and intact sides $(1.17, \mathrm{SD}=0.19)$ was nearly significantly different from that

Figure 1. Photomicrographs illustrating the distribution of SPLI and LENKLI in the V brain-stem complex of the rat. $A-D$, Transverse sections stained with cresyl violet for definition of the borders of V brain-stem nuclei. $\operatorname{Pr} V$, principalis; $S p O$, subnucleus oralis; $S p I$, subnucleus interpolaris; $S p C$, subnucleus caudalis; $\operatorname{Tr} V$, V spinal tract. $E-H$, Distribution of SPLI in sections from the same levels as those illustrated in $A-D$. The arrow in $G$ denotes the heavy immunostaining in the paratrigeminal nucleus. Note also the heavy staining in layers I and II of SpC. I- $L$, Sections reacted for LENKLI. The arrow in $K$ indicates labeling in the paratrigeminal nucleus. Note also the heavy immunoreactivity in layers I and II of caudalis. Calibration bar, $500 \mu \mathrm{m}(A-L)$. 

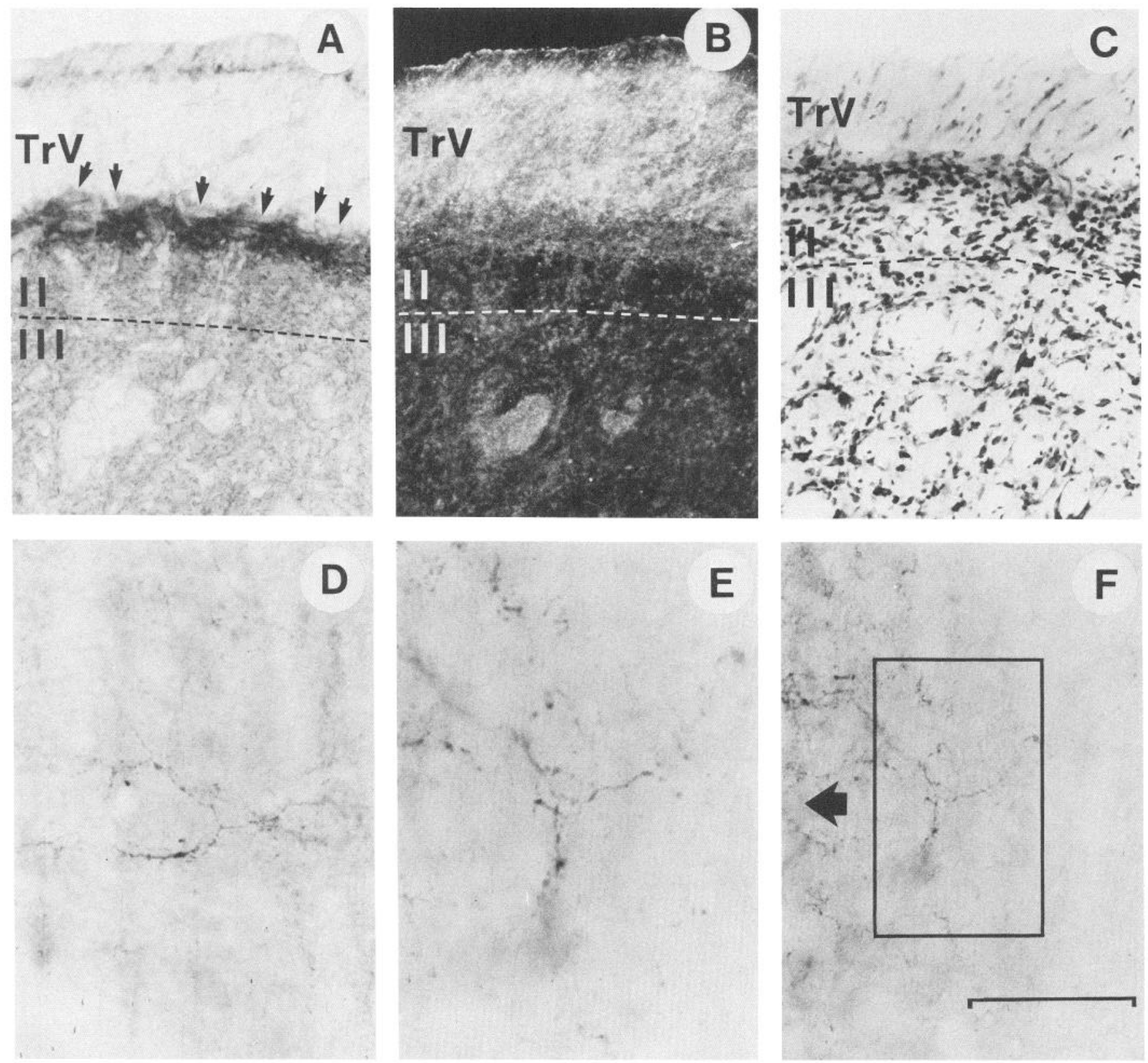

Figure 3. Photomicrographs illustrating details of the distribution of SPLI in subnucleus caudalis. $A$, Bright-field photomicrograph that depicts the distribution of SPLI in subnucleus caudalis of a normal rat. Dashed line denotes the lamina I-II border, small arrows denote the upper portion of lamina I in which SPLI is very light. $B$, Dark-field photomicrograph of the same section. $C$, Bright-field photomicrograph of an adjacent section stained with cresyl violet. $D-F$, Substance P-positive fibers in lamina III-IV and V. $E$, Higher-power photomicrograph of $b o x e d$ area in $F$. Calibration bar: $250 \mu \mathrm{m}$ for $A-D$ and $F$ and $125 \mu \mathrm{m}$ for $E$.

observed in the normals $(t=2.03, d f=12, p=0.06)$. Furthermore, the band of staining on this side was actually broader than that on the intact side of the brain stem. Data from one neonatally nerve-damaged rat are illustrated in Figure 6. The trigeminal spinal tract is substantially shrunken, but the band of staining on the deafferented side is considerably wider than that on the intact side. The cross-sectional area of SPLI on the deafferented $( \pm \mathrm{SD})$ side was $91.7 \pm 12.8 \%$ of that on the intact side (Table $2 \mathrm{~A}$ ). This difference was not statistically significant $(t=1.5, d f=4, p>0.3)$. The small reduction in the area of SPLI on the deafferented side was associated with a larger $(16.5 \pm$ $6.9 \%$ ) decrement in the perimeter of the band of SPLI on this side $(t=4.55, d f=4, p<0.02)$. The fact that a significant reduction in perimeter did not produce a like decrement in area was due to the fact that the band on the deafferented side was $40.5 \pm 22.9 \%$ wider than that on the intact side $(t=3.49, d f=$ $4, p<0.03$ ).

Interpretation of the result described in the preceding paragraph requires additional information regarding the effect of neonatal IO nerve transection upon the cross-sectional area, perimeter, and width of layers I and II. Our evaluation of cresyl violet-stained sections (Fig. 7) demonstrated a $4.1 \pm 16.0 \%$ reduction in the average cross-sectional area of layers I and II and a $20.7 \pm 6.2 \%$ decrease in their average perimeter (Table 

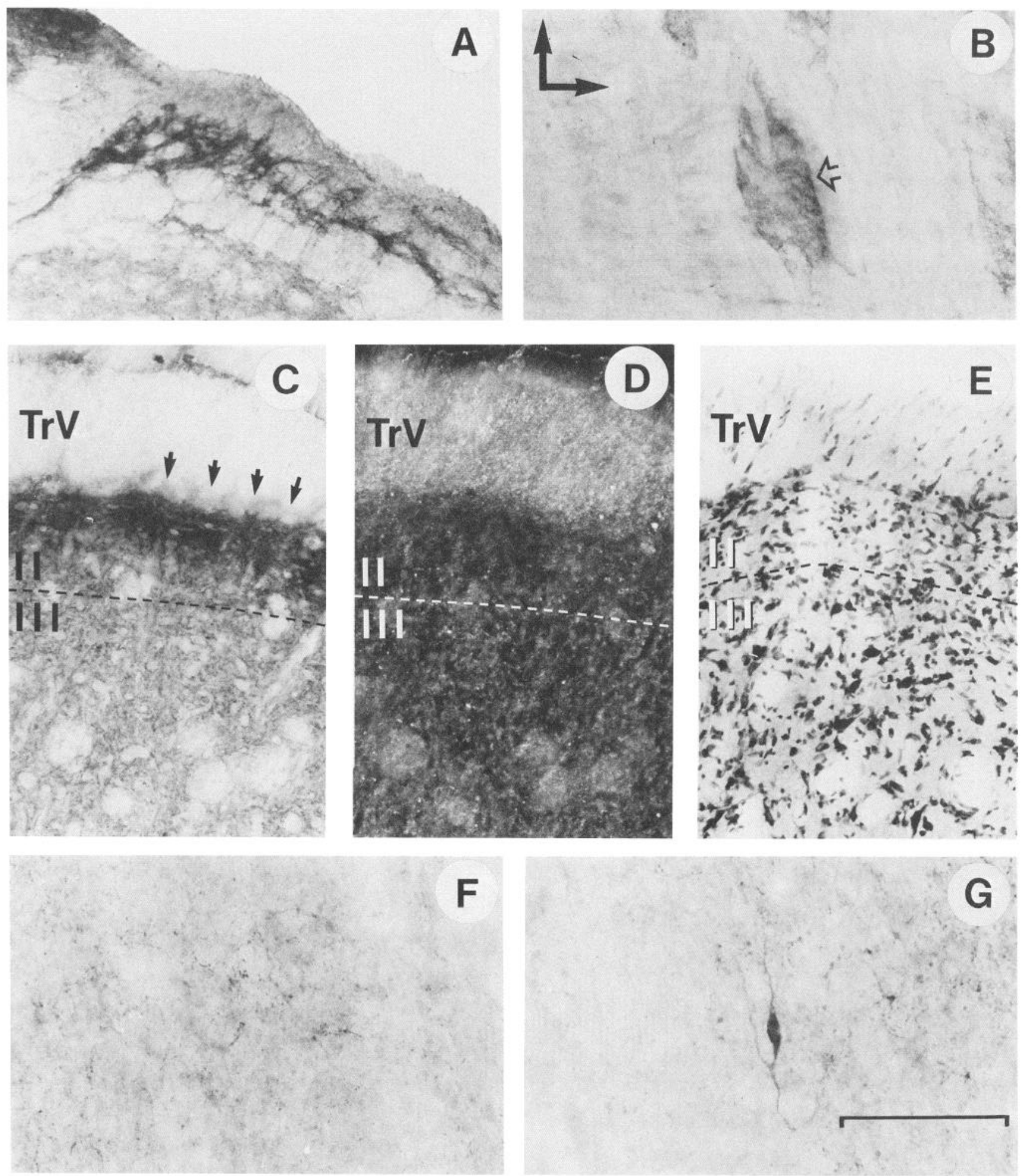

Figure 4. Details of LENKLI in caudal interpolaris and subnucleus caudalis of a normal rat. $A$, Meshwork of immunoreactive fibers in the paratrigeminal nucleus. $B$, Interstitial pocket of LENKLI (horizontal section; arrows point rostrally and laterally). $C$, Bright-field photomicrograph that shows the heavy LENKLI in layers I and II of caudalis. Note the region of very light staining (arrows) just ventral to TrV. $D$, Same section in a dark-field photomicrograph. $E$, Adjacent cresyl violet-stained section. $F$, Light LENKLI in layers II-V. $G$, Immunoreactive cell in layer V. Calibration bar, $250 \mu \mathrm{m}$ for $A-F$ and $125 \mu \mathrm{m}$ for $G$.

2B). There was also a slight, but significant increase in the width of these laminae $(7.2 \pm 3.8 \%, t=4.09, d f=4, p<0.02)$. Thus, on the intact side of the brain stem (Fig. 8, $C$ and $D$ ), the band of SPLI occupied $21.9 \pm 3.5 \%$ the width of layers I and II. On the deafferented side (Fig. $8, A, B$ ), this fraction increased to $40.3 \pm 4.3 \%(t=8.69, d f=4, p<0.001)$. Two alterations in the distribution of SPLI were responsible for this change. First, the region of light staining in upper lamina I was filled with 

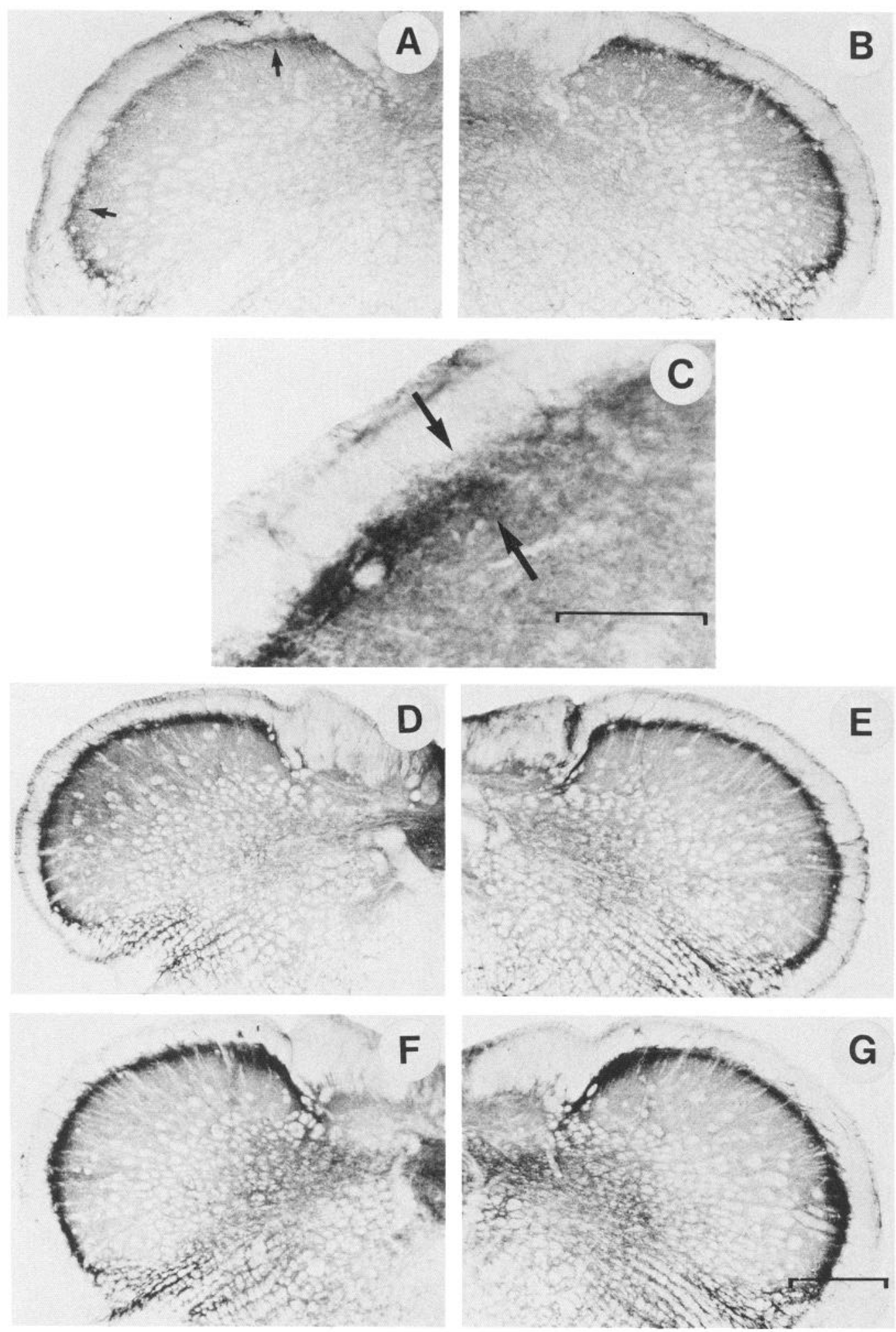

Figure 5. Results obtained with transection of the IO nerve in adult rats. $A$ and $B$, Subnucleus caudalis on 2 sides of the same transverse section from a rat that sustained transection of the IO nerve $10 \mathrm{~d}$ prior to sacrifice. Note the reduction in SPLI in the portion of caudalis (between the arrowheads) normally innervated by the IO nerve. $C$, Higher-power photomicrograph of the deafferented side of the brain stem from an adjacent section. Note the reduction in the density of staining (arrows) at the boundary of IO central territory in layers I and II. $D$ and $E$, Two sides from the same section stained for SPLI in a rat that sustained transection of the IO nerve $60 \mathrm{~d}$ prior to sacrifice. There is no qualitative difference in the density of SPLI on the deafferented $(D)$ and intact $(E)$ sides. $F$ and $G$, Both sides of the brain stem in a section reacted for LENKLI from a rat that sustained transection of the IO nerve $10 \mathrm{~d}$ prior to sacrifice. There are no qualitative differences between the distributions and densities of the staining on the 2 sides. Calibration bar: $C, 250 \mu \mathrm{m} ; G, 500 \mu \mathrm{m}$ (also applies to $A, B$, and $D-F$ ). 

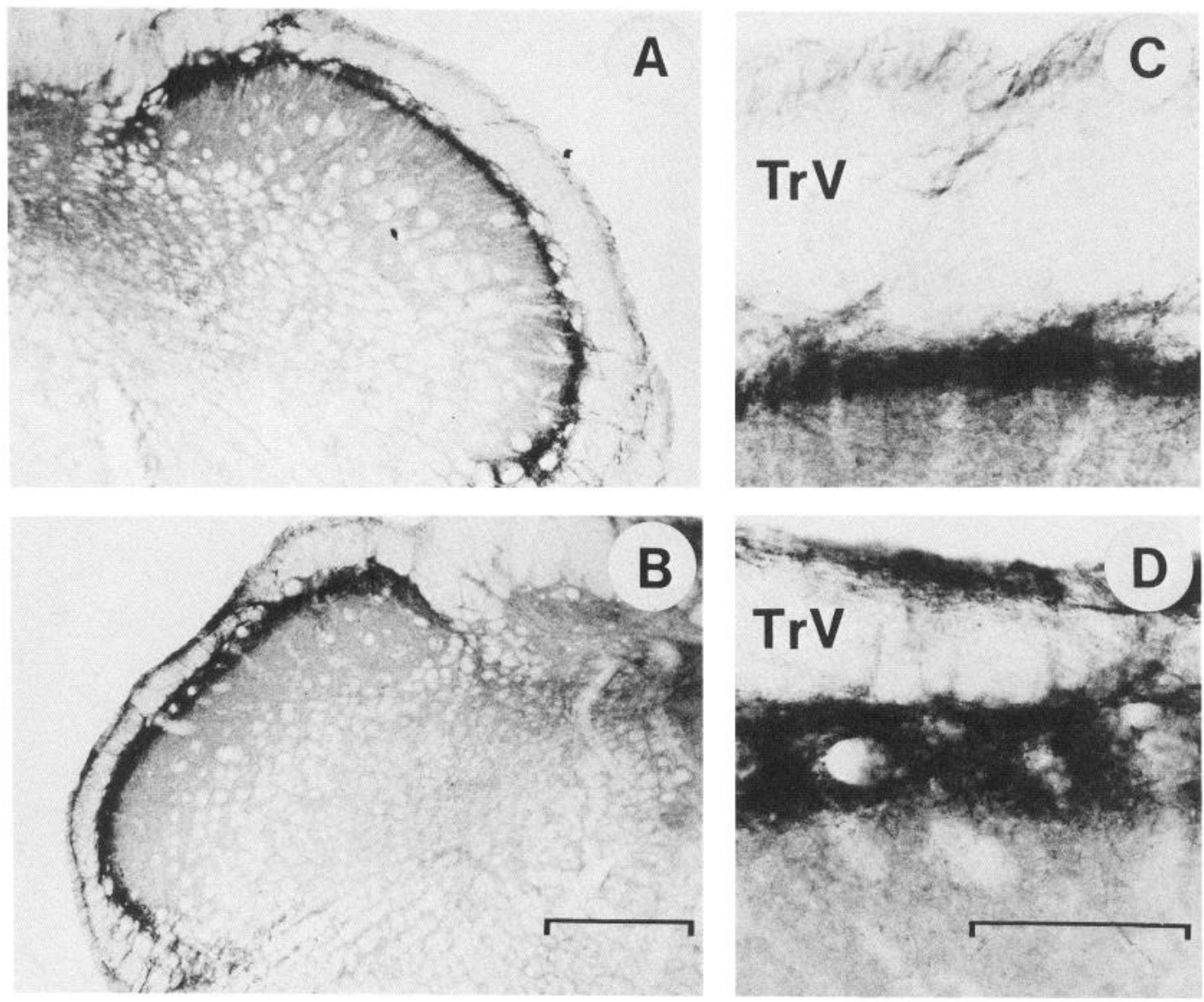

Figure 6. Photomicrographs illustrating the effect of neonatal transection of the IO nerve on the distribution of SPLI in subnucleus caudalis. $A$ Intact side; $B$, deafferented side of caudalis. $C$ and $D$, Higher-power micrographs of the SPLI in caudalis on the intact $(C)$ and deafferented $(D)$ sides of the brain stem. Note that, while subnucleus caudalis is clearly shrunken on the deafferented side, the band of SPLI in layers I and II is clearly wider. Note also that the region of light labeling in the upper portion of lamina $I$ that is observed in normals and the intact side of nerve damaged animals is very heavily labeled on the deafferented side of the brain stem. Calibration: $A$ and $B, 500 \mu \mathrm{m} ; C$ and $D, 250 \mu \mathrm{m}$.

Table 1. Ratios of optical density of SPLI on the partially deafferented side of the brain stem to that on the intact side in the various nerve damaged rats used in this study $(A-D)$

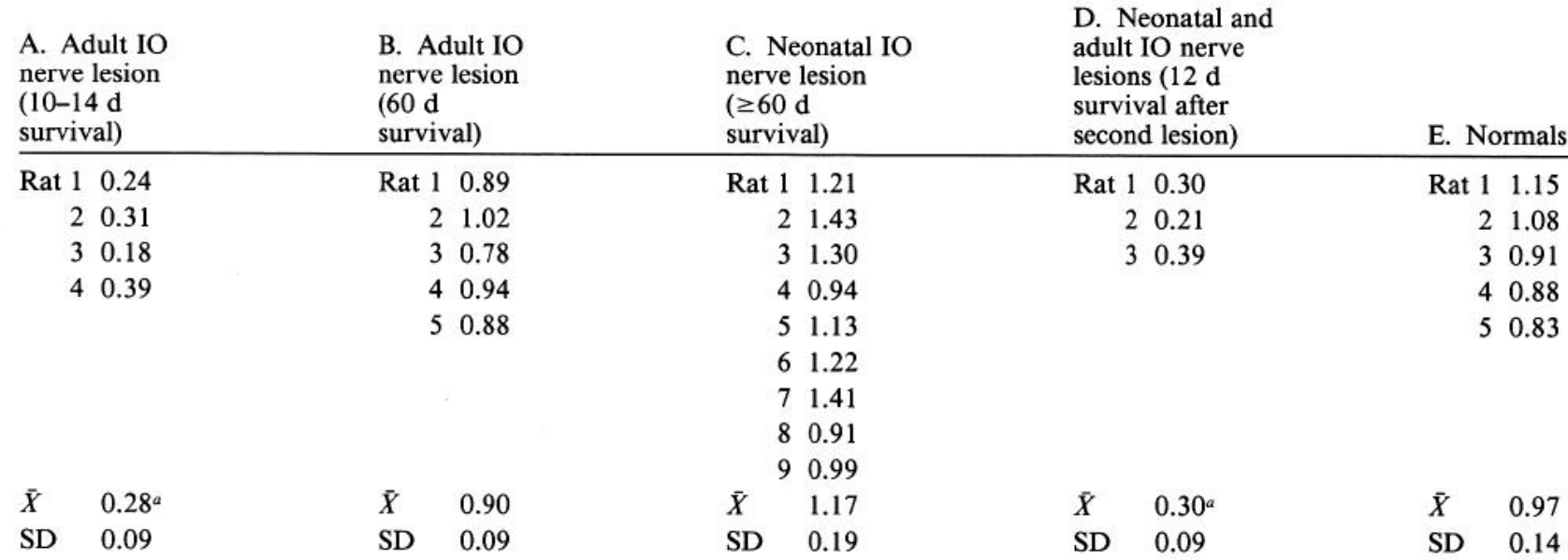

Data from 5 normal (E) animals are also presented for purposes of comparison.

${ }^{a}$ Significant difference between the average ratio observed for a group of nerve damaged rats and that for the normals (independent $t$ test, $p<0.05$ ). 

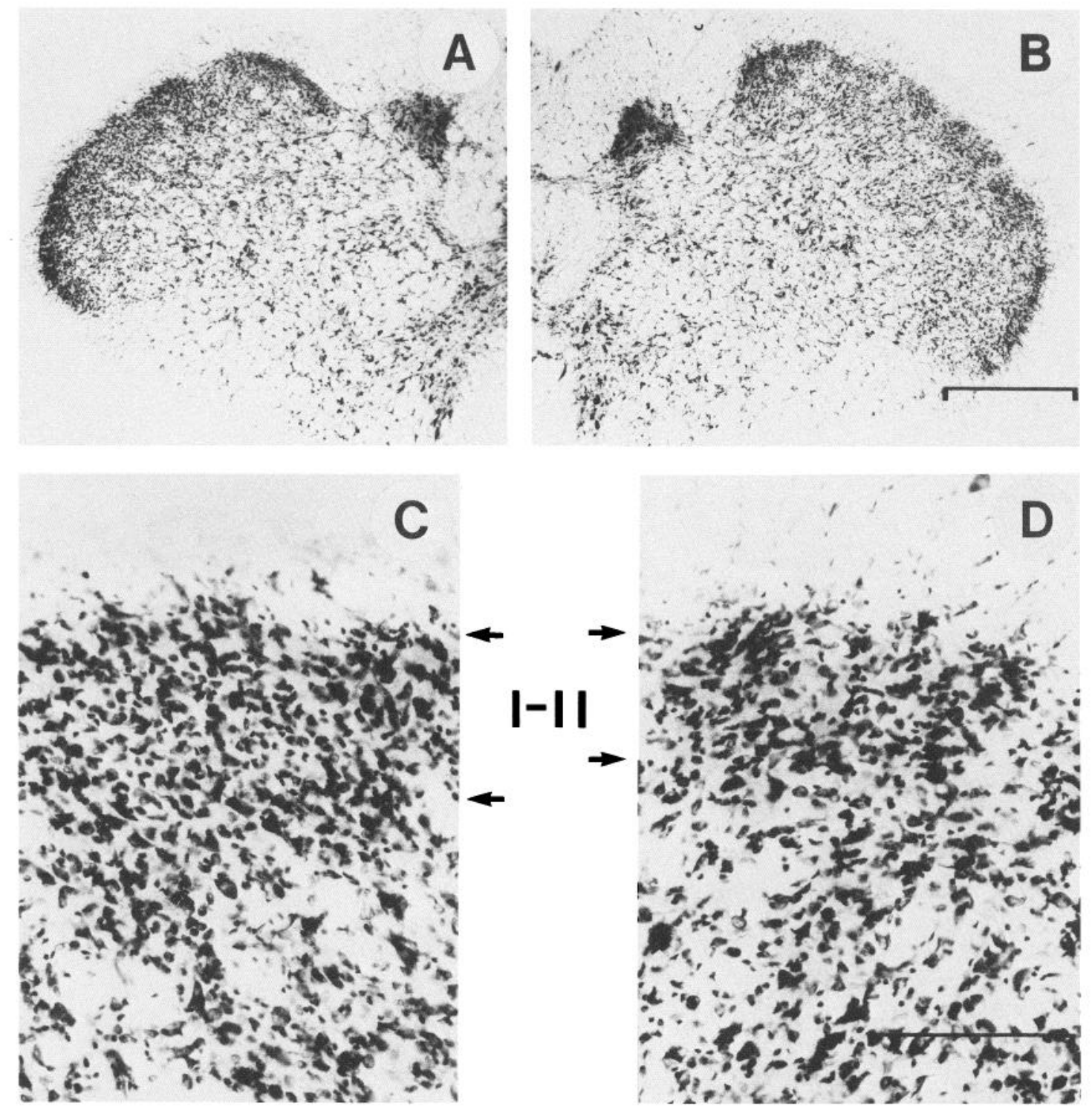

Figure 7. Photomicrographs that show the effect of neonatal IO nerve section upon the width of layers I and II in caudalis. $A$ and $B$, Low-power photomicrographs through the middle of the anteroposterior extent of caudalis. Note the shrinkage of the entire nucleus on the deafferented (left) side. $C$ and $D$, Higher-power photomicrographs made from these same sections. Note that layers I and II are slightly thicker on the deafferented side. Calibration bar: $A$ and $B, 500 \mu \mathrm{m} ; C$ and $D, 250 \mu \mathrm{m}$.

heavy SPLI (Fig. $8 \mathrm{~A}$, also see Fig. $6 \mathrm{~A}$ ), and second, the band of immunostaining extended deeper into layer II.

Neonatal transection of the IO nerve produced slight reductions in the cross-sectional areas and perimeters of LENKLI in layers I and II of caudalis (Fig. 9, Table 2C).

\section{Source of the SPLI in caudalis of the neontally nerve- damaged rats}

We recut the IO nerve in 3 adult animals that had previously sustained neonatal transection of the same nerve, waited $12 \mathrm{~d}$, and then sacrificed the rats and processed their brains for the demonstration of SPLI. All 3 of these animals had a markedly reduced density of SPLI on the deafferented side of the brain stem (Fig.10, Table 1D). This result is consistent with the conclusion that primary afferent fibers are at least partially responsible for the dense SPLI observed in adult rats that have sustained neonatal transection of the IO nerve.

\section{Discussion}

Normal organization of SPLI and LENKLI in the rat's $V$ brain-stem complex

Overall, the distributions of SPLI and LENKLI that we observed in normal rats agreed closely with those previously reported by other investigators (e.g., Hökfelt et al., 1975; Del Fiacco and Cuello, 1980; Sakanaka et al., 1982). Little SPLI was present in the principalis, oralis, or rostral interpolaris. The most rostral regions that contained dense SPLI and LENKLI were the interstitial pockets of caudal interpolaris and the paratrigeminal nucleus. Ljungdahl et al. (1978) reported "islands" of substance P-positive fibers in the caudal portion of interpolaris in the rat, and Schults et al. (1985) have also noted rostral islands of substance P staining in cat in a region, which they refer to as the interstitial nucleus of $\operatorname{TrV}$ (also see Falls and Phelan, 1984). As in our material, this region also stained for leucine enkephalin in the cat (Schults et al., 1985). 

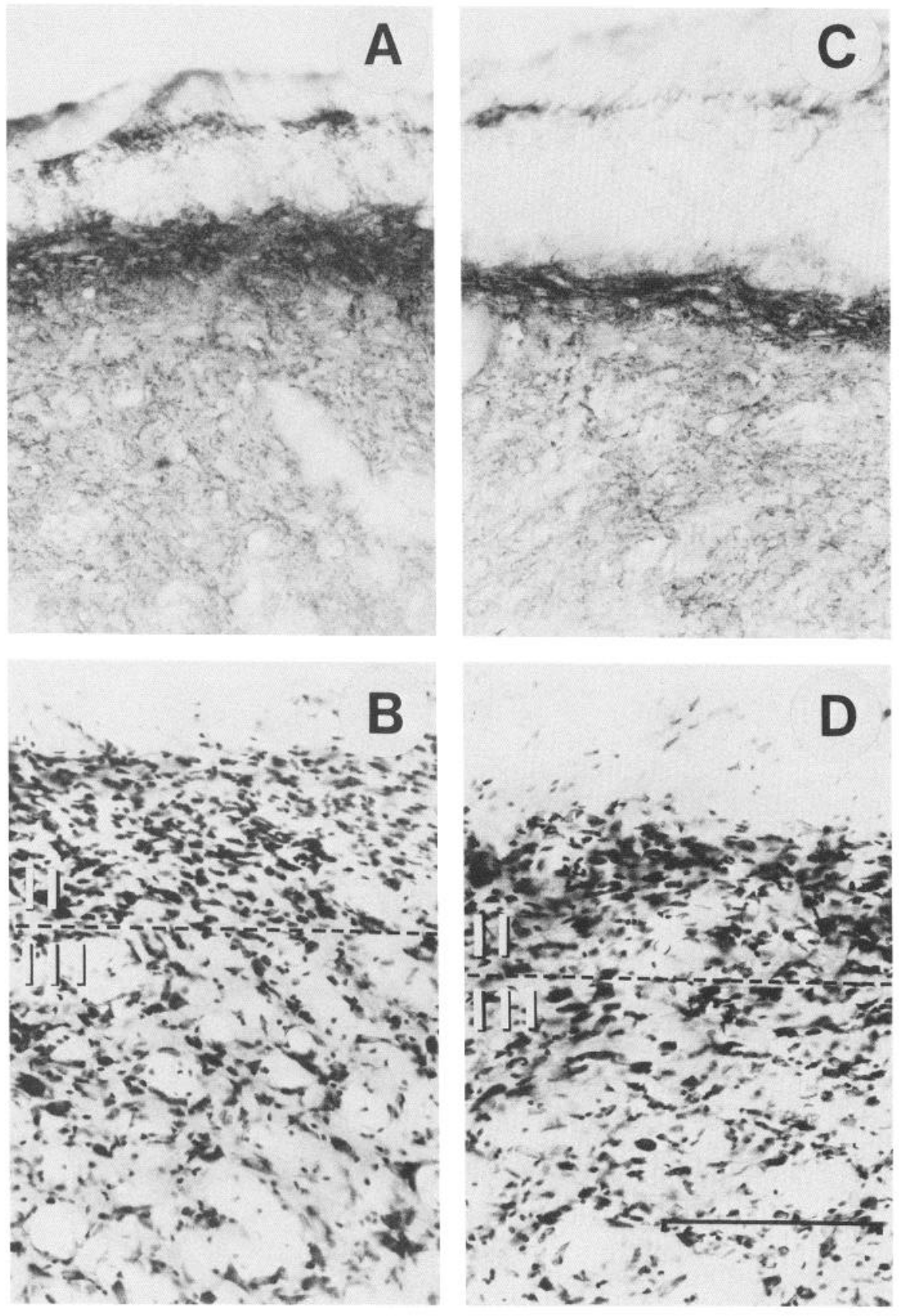

Figure 8. Photomicrographs illustrating the relationship between the width of the region of heavy SPLI and that of lamina I-II in a single nerve-damaged animal. In these sections, heavy SPLI subtends $44 \%$ of the width of layers I and II on the deafferented side $(A$ and $B$ ). On the intact side ( $C$ and $D$ ), SPLI occupies $24 \%$ of the width of layers I and II. Calibration bar, $250 \mu \mathrm{m}$ (applies to all panels).

\section{Effects of IO nerve transection in adult rats}

The reduction in SPLI observed in rats that sustained transection of the IO nerve as adults corresponds well with the results of other investigators who have examined effects of peripheral nerve transections upon substance $P$ in the brain stem and spinal cord. Barbut et al. (1981), McGregor et al. (1984), and Tessler et al. (1985) have all reported that transection of the sciatic nerve produces a reduction in the density of substance $\mathrm{P}$ immunoreactivity in the spinal cord. Jessel et al. (1979) and McGregor et al. (1984) obtained corresponding results with radioimmunoassay.

The results of Jessel et al. (1979) and Barbut et al. (1981) differed from our own in that they observed no recovery of SPLI after nerve transection. In the case of Barbut et al. (1981), this might be explained by the their ligation of the damaged nerve which prevented its regeneration. Jessel et al. (1979), however, took no special measures to prevent regeneration. Tessler et al. (1985) did observe a recovery of SPLI at long (over $100 \mathrm{~d}$ ) intervals after sciatic nerve section and ligation in adult cats. They attributed this recovery to sprouting by central neurons (see Tessler et al., 1980, 1981, and also Micevych et al., 1986). To our knowledge, the effects of peripheral nerve section upon central SPLI have not been examined within the $\mathrm{V}$ system. Several investigators (e.g., Hökfelt et al., 1977; Cuello et al., 1978; Del Fiacco and Cuello, 1980) have, however, noted that transection of the $\mathrm{V}$ sensory root or lesions of the $\mathrm{V}$ ganglion itself result in a depletion of SPLI in the V brain-stem complex. None of these investigators reported any recovery of SPLI at long intervals after such lesions. This last point is important 

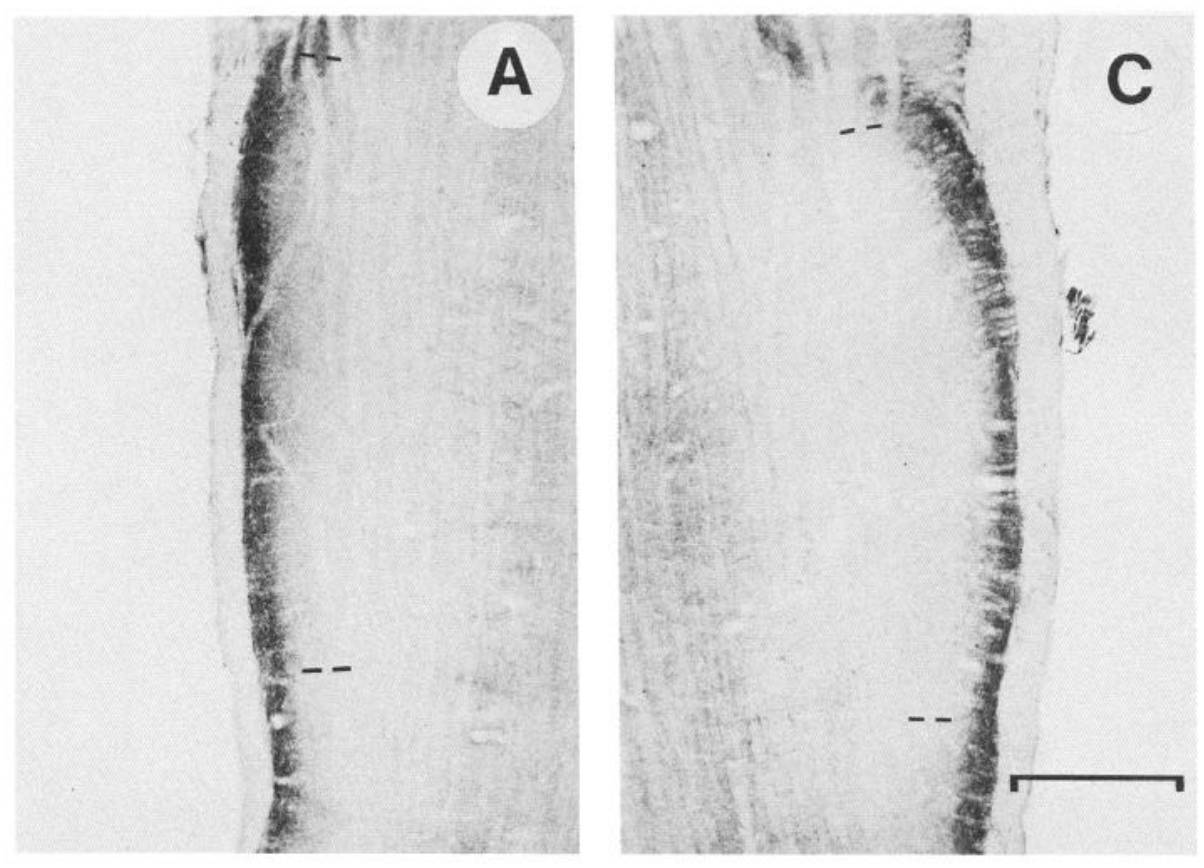

Figure 9. Effect of neonatal transection of the IO nerve upon the distribution of LENKLI in the rat's $\mathrm{V}$ brainstem complex. All photomicrographs are from the same horizontal section. $A$ and $C$, Deafferented side; $B$ and $D$, intact side. Dashed lines denote the rostral and caudal boundaries of caudalis. Calibration bar: $A$ and $C, 500 \mu \mathrm{m} ; 250$ $\mu \mathrm{m}, B$ and $D$.
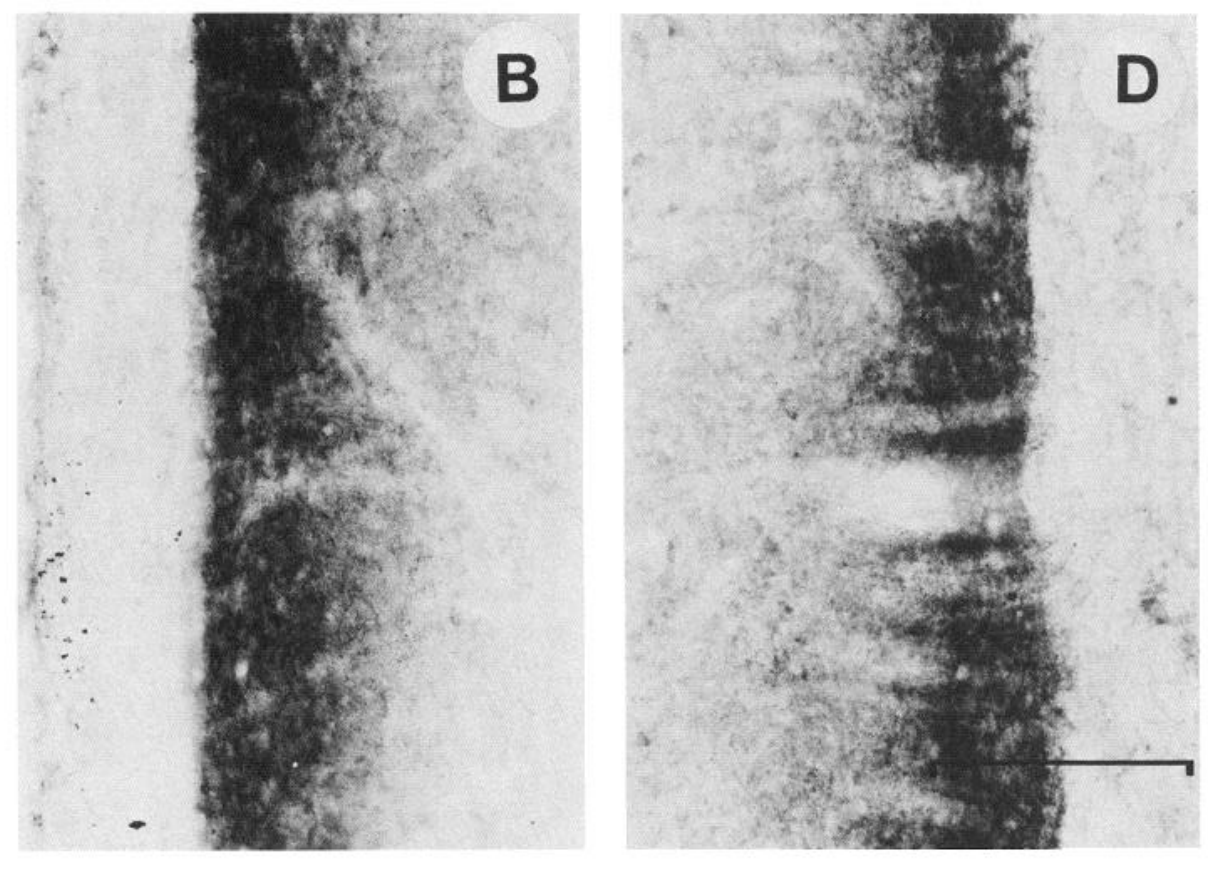

because it also suggests, as do our own results, that the recovery of SPLI is due to primary afferents rather than brain-stem neurons (also see below).

The fact that IO nerve lesions did not alter LENKLI in the $\mathrm{V}$ brain-stem complex is consistent with previous observations of Del Fiacco and Cuello (1980) and Micevych et al. (1986).

\section{Effects of neonatal IO nerve transection upon the distribution of SPLI and LENKLI in the rodent $V$ brain-stem complex}

The effect of neonatal IO nerve transection was qualitatively different from that which followed adult lesions of this $\mathrm{V}$ branch. Neonatal transection of the IO nerve increased the portion of layers I and II that contained heavy SPLI, and this coincides well with the results of anterograde tracing experiments previously carried out in rats that sustained similar lesions. Tran- section of the IO nerve in newborn rats resulted in a substantial alteration in its innervation of the brain stem. There was a marked reduction in the transganglionic labeling observed in all $\mathrm{V}$ subnuclei after application of HRP to the regenerate nerve, but this decrement was least substantial in layers I and II of caudalis (Jacquin and Rhoades, 1983, 1985; Chiaia et. al., 1987).

This combination of results suggests the possibility that many or most of the $\mathrm{V}$ ganglion cells that are axotomized, but ultimately survive transection of the IO nerve, may be substance $\mathrm{P}$ immunoreactive. Such a suggestion is, at this point, highly speculative, and data that we have obtained in some other experiments indicate that this may not be the case. The cells in sensory ganglia that are labeled by substance $\mathrm{P}$ antibodies are generally small or medium in size (e.g., Price, 1985). If IO nerve transection results in a differential survival of the IO ganglion 

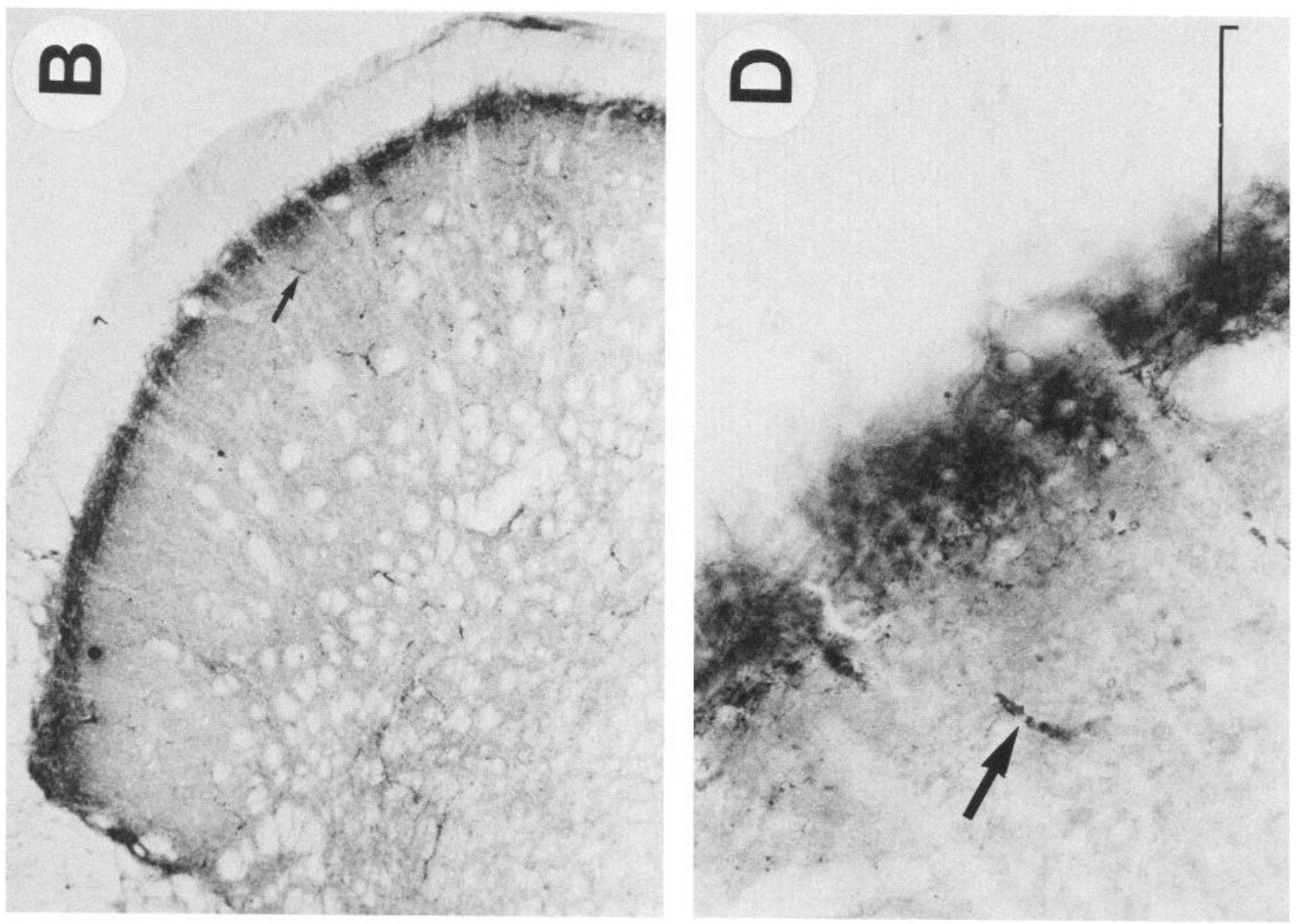

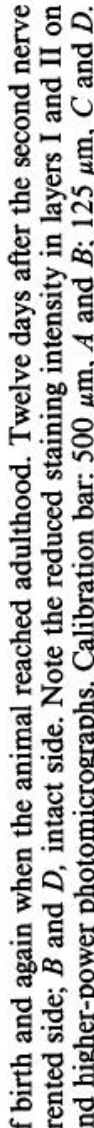
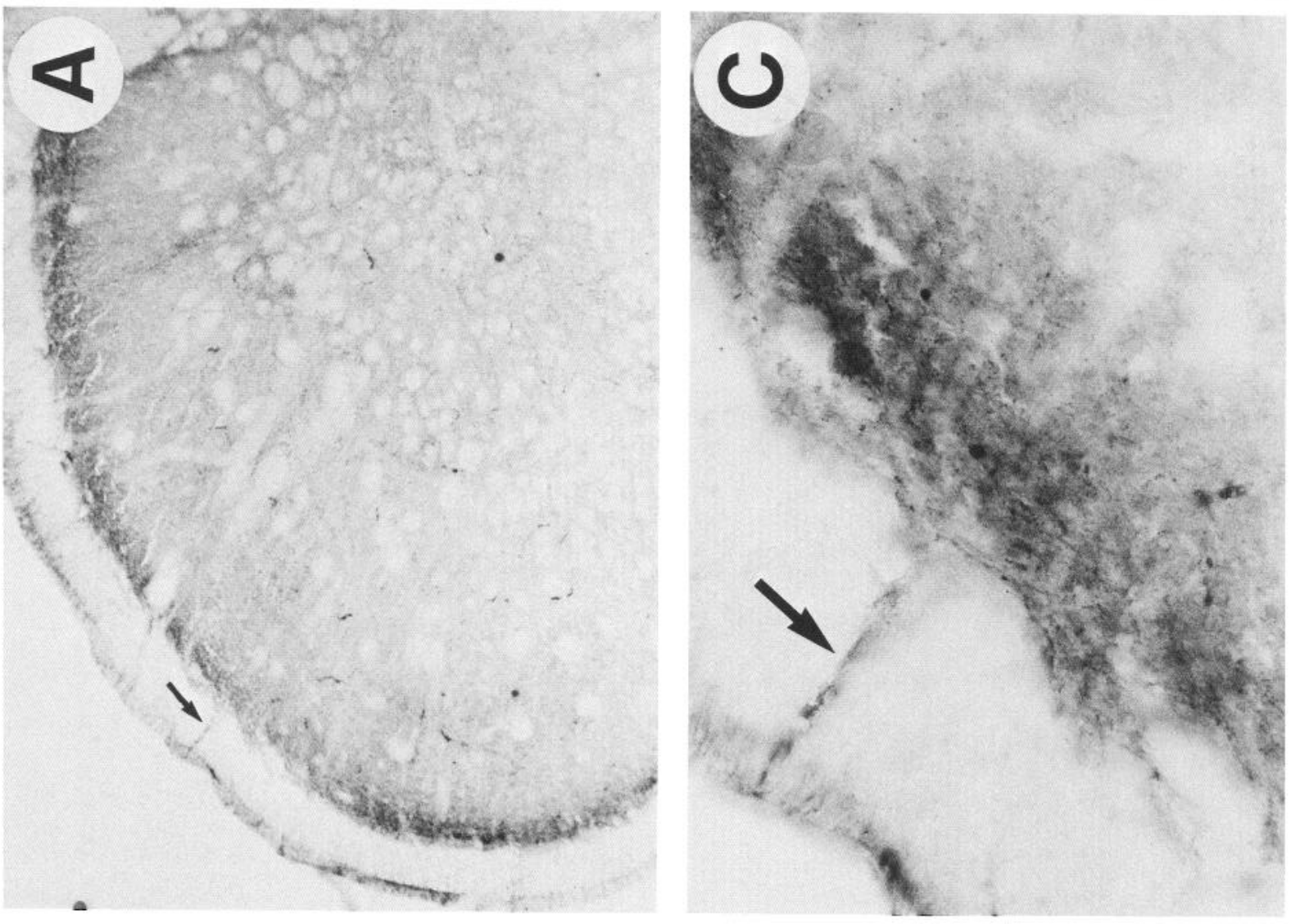

政

讨

홈․․

政

適与

द

塎

要

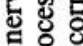

을 은

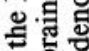

율

उद

롱

든.

象突

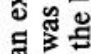

뜽

늑를

幽

ㅇ.ㅇ․․

o

s. 
Table 2. Effects of neonatal IO nerve transection upon distribution of SPLI in subnucleus caudalis

\begin{tabular}{llcc} 
Rat & Area & Perimeter & Width \\
\hline \multirow{4}{*}{$\begin{array}{llll}\text { A. SPLI deafferented/normal (\%) } \\
2\end{array}$} & 112.5 & 86.4 & \\
\cline { 2 - 4 } 3 & 83.9 & 74.2 & 172.5 \\
4 & 88.2 & 91.0 & 113.3 \\
5 & 94.0 & 87.5 & 131.0 \\
$\bar{X}$ & 79.9 & 78.5 & 154.0 \\
SD & 91.7 & $83.5^{a}$ & 131.9 \\
& 12.8 & 6.9 & $140.5^{a}$
\end{tabular}

B. Layers I and II deafferented/normal (\%)

\begin{tabular}{lccc} 
& 114.0 & 72.1 & 106.7 \\
2 & 88.8 & 88.9 & 110.9 \\
3 & 102.0 & 76.5 & 104.4 \\
4 & 102.4 & 78.3 & 111.2 \\
5 & 72.2 & 80.6 & 102.6 \\
$\bar{X}$ & 95.9 & $79.3^{a}$ & $107.2^{a}$ \\
$\mathrm{SD}$ & 16.0 & 6.2 & 3.8 \\
& C. LENKLI deafferented/normal (\%) & \\
\hline & 81.8 & 66.1 & 108.5 \\
2 & 90.2 & 91.8 & 103.1 \\
3 & 80.7 & 75.7 & 115.1 \\
4 & 89.9 & 95.6 & 89.4 \\
5 & 83.9 & 87.0 & 84.4 \\
$\bar{X}$ & $85.1^{a}$ & $83.2^{a}$ & 100.2 \\
$\mathrm{SD}$ & 4.3 & 12.1 & 13.09
\end{tabular}

B. Effect of neonatal IO nerve transection upon dimensions of layers I and II of subnucleus caudalis. C. Effect of neonatal nerve section upon distribution of LENKLI in subnucleus caudalis.

All data are presented as percentages of cross-sectional areas, perimeters, or widths measured on the intact side of the same animal.

${ }^{a} p<0.05$ on a 2 -tailed $t$ test.

cells that contain substance $P$, it might be expected that the same lesion would result in a differential survival of smaller ganglion cells. This is not the case. Neonatal transection of the IO nerve does not significantly alter the distribution of soma diameters of the $\mathrm{V}$ ganglion cells that contribute axons to the regenerate IO nerve (Chiaia et al., 1987).

The data from the experiments in which the nerve was transected once in infancy and a second time in adulthood indicated that at least a portion of the abnormally widespread SPLI observed after neonatal 10 nerve section arose from primary afferents. This is also consistent with the anterograde tracing data described above and suggests the possibility that substance $\mathrm{P}$ synthesizing ganglion cells, regardless of their relative numbers, may be more successful than other primary afferents in maintaining or reestablishing their projections to the brain stem after damage to their pcriphcral axons.

One other possible explanation of our results is that lategrowing IO nerve axons from substance $P$ synthesizing ganglion cells may have "escaped" our lesions. Neurogenesis in the V ganglion is complete by embryonic day $13,9 \mathrm{~d}$ prior to birth (Forbes and Welt, 1981). However, Munger and Rice (1986) have provided data indicating that the IO innervation of the vibrissa pad is far from complete on the day of birth. While our lesions were quite proximal to the region investigated by Munger and Rice (1986) and electron microscopic data (Renehan and Rhoades, 1984) have indicated that the IO nerve contains more fibers at birth than it will in adulthood, it is still possible that the net reduction of IO axons reflects both addition and loss of fibers and that undamaged axons grew past the point of our lesions. However, one additional finding from our laboratory suggests that this was not the case. Chiaia et al. (1987) showed that single transection of the IO nerve on the day of birth resulted in the same number of surviving IO ganglion cells as that observed in rats that sustained such lesions on the day of birth and once each subsequent week until the time of a terminal experiment. If a significant number of fibers had not grown past the point of the lesion by the day of birth, one would expect to observe a greater number of $\mathrm{IO}$ ganglion cells in the rats that sustained IO nerve damage only on the day of birth.

The results that we have obtained for SPLI in the medullary dorsal horn are very different from those that Fitzgerald (1985) has provided for fluoride-resistant acid phosphatase (FRAP)positive primary afferents that innervate the lumbar spinal cord. Here, neonatal transection of the sciatic nerve produces a permanent gap in the FRAP staining in lamina II. Furthermore, the "filling in" that is observed is the result of sprouting by other, undamaged primary afferents. When combined with Nagy and Hunt's (1982) finding that FRAP and substance P are localized in different subpopulations of sensory ganglion cells (however, see Dalsgaard et al., 1984, for data that suggest that FRAP and SPU coexist about $5 \%$ of sensory ganglion cells), our results and those of Fitzgerald (1985) suggest strongly that different subpopulations of sensory ganglion cells may respond very differently to transection of their peripheral axons.

\section{References}

Aldskogius, II., J. Arvidsson, and G. Grant (1985) The reaction of primary sensory neurons to peripheral nerve injury with particular emphasis on transganglionic changes. Brain Res. Rev. 10: 27-46.

Arvidsson, J. (1982) Somatotopic organization of vibrissae afferents in the trigeminal sensory nuclei of the rat studied by transganglionic transport of HRP. J. Comp. Neurol. 211: 84-92.

Arvidsson, J. (1986) Transganglionic degeneration in vibrissae innervating primary sensory neurons of the rat: $\mathrm{A}$ light and electron microscopic study. J. Comp. Neurol. 249: 392-403.

Barbut, D., J. M. Polak, and P. D. Wall (1981) Substance P in spinal cord dorsal horn decreases following peripheral nerve injury. Brain Res. 205: 289-298.

Chiaia, N. L., P. R. Hess, and R. W. Rhoades (1987) Preventing regeneration of infraorbital axons does not alter the ganglionic or transganglionic conscquences of nconatal transection of this trigeminal branch. Dev. Brain Res. 36: 75-88.

Cuello, A. C., and I. Kanazawa (1978) The distribution of substance $P$ immunoreactive fibers in the rat central nervous system. J. Comp. Neurol. 178: 129-156.

Cuello, A. C., M. D. Fiacco, and G. Paxinos (1978) The central and peripheral ends of the substance $\mathrm{P}$-containing sensory neurones in the rat trigeminal system. Brain Res. 152: 499-509.

Cuello, A. C., J. V. Priestley, and G. Paxinos (1985) Substance P and enkephalin containing pathways. In The Rat Nervous System, G. Paxinos and C. Watson, eds., pp. 441-469, Academic, North Ryde, Australia.

Dalsgaard, C.-J., J. Ygge, S. R. Vincent, M. Ohrling, G. J. Dockray, and R. Elde (1984) Peripheral projections and neuropeptide coexistence in a subpopulation of fluoridc-rcsistant acid phosphatase reactive spinal primary sensory neurons. Neurosci. Lett. 51: 139-144.

Del Fiacco, M., and A. C. Cuello (1980) Substance P- and enkephalincontaining neurons in the rat trigeminal system. Neuroscience $5: 803-$ 815.

Falls, W. M., and K. D. Phelan (1984) The interstitial nucleus of the spinal V tract: Anatomical organization and patterns of connectivity. Soc. Neurosci. Abstr. 10: 482. 
Fitzgerald, M. (1985) The sprouting of saphenous nerve terminals in the spinal cord following early postnatal sciatic nerve section in the rat. J. Comp. Neurol. 240: 407-413.

Fitzgerald, M., and G. Vrbová (1985) Plasticity of acid phosphatase (FRAP) afferent terminal fields and of dorsal horn cell growth in the neonatal rat. J. Comp. Neurol. 240: 414-422.

Forbes, D. J., and C. Welt (1981) Neurogenesis in the trigeminal ganglion of the albino rat: A quantitative autoradiographic study. J. Comp. Neurol. 199: 133-147.

Grant, G., and J. Arvidsson (1975) Transganglionic degeneration in trigeminal primary sensory neurons. Brain Res. 95: 265-279.

Hökfelt, T., J. O. Kellerth, G. Nilsson, and B. Pernow (1975) Substance P: Localization in the central nervous system and in some primary sensory neurons. Science 190: 889-890.

Hökfelt, T., A. Ljungdahl, L. Terenius, R. Elde, and G. Nilsson (1977) Immunohistochemical analysis of peptide pathways possibly related to pain and analgesia: Enkephalin and substance P. Proc. Natl. Acad. Sci. USA 74: 3081-3085.

Hsu, S. M., L. Raine, and H. Farger (1981) Use of avidin-biotinperoxidase complex $(\mathrm{ABC})$ in immunoperoxidase techniques - a comparison between $\mathrm{ABC}$ and unlabeled antibody (PAP) procedures. J. Histochem. Biochem. 29: 577-580.

Jacquin, M. F., and R. W. Rhoades (1983) Central projections of the normal and "regenerate" infraorbital nerve in adult rats subjected to neonatal unilateral infraorbital lesions: A transganglionic horseradish peroxidase study. Brain Res. 269: 137-144.

Jacquin, M. F., and R. W. Rhoades (1985) Effects of neonatal infraorbital lesions upon central trigeminal primary afferent projections in rat and hamster. J. Comp. Neurol. 235: 129-143.

Jacquin, M. F., R. D. Mooney, and R. W. Rhoades (1984) Altered somatosensory receptive fields in hamster colliculus after infaraorbital nerve section and xylocaine injection. J. Physiol. (Lond.) 348: 471492.

Jessel, T., A. Tsunoo, I. Kanazawa, and M. Otsuka (1979) Substance P: Depletion in the dorsal horn of rat spinal cord after section of the peripheral processes of primary sensory neurons. Brain Res. 168:247259.

Knyihar, E., and B. Csillik (1976) Effect of peripheral axotomy on the fine structure and histochemistry of Rolando substance: Degeneration atrophy of central processes of pseudounipolar cells. Exp. Brain Res. 26: 73-87.

Ljungdahl, A., T. Hökfelt, and G. Nilsson (1978) Distribution of substance P-like immunoreactivity in the central nervous system of the rat. I. Cell bodies and nerve terminals. Neuroscience 3: 861-943.

McGregor, G. P., S. J. Gibson, I. M. Sabate, M. A. Blank, N. D. Christofides, P. D. Wall, J. M. Polak, and S. R. Bloom (1984) Effect of peripheral nerve section and nerve crush on spinal cord neuropeptides in the rat; increased VIP and PHI in the dorsal horn. Neuroscience 13: 207-216.

Micevych, P. E., A. Stroink, T. Yaksh, and V. L. W. Go (1986) Immunochemical studies of substance $P$ and cholecystokinin octapeptide recovery in dorsal horn following unilateral lumbosacral ganglionectomy. Somatosens. Res. 3: 239-260.
Munger, B. L., and F. L. Rice (1986) Successive waves of differentiation of cutaneous afferents in rat mystacial skin. J. Comp. Neurol. 252:404-414.

Nagy, J. I., and S. P. Hunt (1982) Fluoride-resistant acid phosphatasecontaining neurones in dorsal root ganglia are separate from those containing substance $P$ or somatostatin. Neuroscience 7: 89-97.

Paxinos, G., and C. Watson (1982) The Rat Brain in Stereotaxic Coordinates, Academic, North Ryde, Australia.

Price, J. (1985) An immunohistochemical and quantitative examination of dorsal root ganglion cell neuronal subpopulations. J. Neurosci. 5: 2051-2059.

Renehan, W. E., and R. W. Rhoades (1984) A quantitative electron microscopic analysis of the infraorbital newborn rat. Brain Res. 322: 369-373.

Renehan, W. E., R. W. Rhoades, B. G. Klein, and M. F. Jacquin (1986) Physiological and anatomical consequences of infraorbital (IO) nerve section in adult rat. Anat. Rec. 214: 107A.

Rustioni, A., S. Sanyal, and H. G. J. M. Kuypers (1971) A histochemical study of the distribution of the trigeminal divisions in the substantia gelatinosa of the rat. Brain Res. 32: 45-52.

Sakanaka, M., S. Inagaka, S. Shiosaka, E. Senba, H. ' lakagi, K. Iakatsuki, Y. Kawai, H. Iida, Y. Hara, and M. Tohyama (1982) Ontogeny of substance P-containing neuron system of the rat: Immunohistochemical analysis. II. Lower brain stem. Neuroscience 7: 10971126.

Seltzer, Z., and M. Devor (1984) Effect of nerve section on the spinal distribution of neighboring nerves. Brain Res. 306: 31-37.

Shults, R. C., A. R. Light, and S. Donaghy (1985) Interstitial nucleus of the spinal trigeminal tract: A specific nociceptive relay for oral and perioral structures? Soc. Neurosci. Abstr. 11: 578.

Simantov, R., M. J. Kuhar, G. R. Uhl, and S. H. Snyder (1977) Opioid peptide enkephalin: Immunohistochemical mapping in rat central nervous system. Proc. Natl. Acad. Sci. USA 74: 2167-2171.

Sugimoto, T., and S. Gobel (1982) Primary neurons maintain their central axonal arbors in the spinal dorsal horn following peripheral nerve injury: An anatomical analysis using transganglionic transport of horseradish peroxidase. Brain Res. 248: 377-381.

Tessler, A., E. Glazer, R. Artymyshyn, M. Murray, and M. E. Goldberger (1980) Recovery of substance $P$ in the cat spinal cord after unilateral lumbosacral deafferentation. Brain Res. 191: 459-470.

Tessler, A., B. T. Himes, R. Artymyshyn, M. Murray, and M. E. Goldberger (1981) Spinal neurons mediate return of substance $P$ following deafferentation of cat spinal cord. Brain Res. 230: 263-281.

Tessler, A., B. T. Himes, N. R. Krieger, M. Murray, and M. E. Goldberger (1985) Sciatic nerve transection produces death of dorsal root ganglion cells and reversible loss of substance $\mathrm{P}$ in spinal cord. Brain Res. 332: 209-218.

Westrum, L. E., R. C. Canfield, and R. G. Black (1976) Transganglionic degeneration in the spinal trigeminal nucleus following removal of tooth pulps in adult cats. Brain Res. 101: 137-140. 